\title{
FACTORS AFFECTING THE EXCHANGE RATE IN SUDAN (1972-2013)
}

\section{MULHEM YOUSIF DAF ALLA ${ }^{1} \&$ SIHAM ABDALATEEF AHMED ${ }^{2}$}

\author{
${ }^{1}$ Basic Science Unit, Preparatory Year Deanship, Prince Sattam Bin Abdulaziz University, Saudi Arabia
}

${ }^{2}$ Basic Science Unit, Preparatory Year Deanship, Al-Ghad International Health Sciences Colleges, Saudi Arabia

\begin{abstract}
Since independence, Sudan has experienced poor economic performance attributed to external as well as domestic factors, particularly policy failure and resource mismanagement. However, Exchange rate policy is one of the most important price policy tools and it is directly linking to the current account situation of the country.

This study performs to test hypotheses, based on stationary tests (unit root test) focusing on the augmented Dickey fuller test and make a co-integration test by using the method of (Johansson test) to ensure the existence of a long-term equilibrium relationship between the variables of the model. Moreover, estimated model parameters by ordinary least squares (OLS) for the econometric model. In addition, need to match the estimated model according to economic, statistical criteria and it is free of the econometric problems. On the other hand, the model should be having the predictive ability tested by Thiele inequality coefficient.

The results of statistical tests showed that the variables of the study suffer non-stationary, but stable levels in the first difference at the level of significance (5\%) except exchange rate was stable in the second difference. Moreover, the results reveal a balance in the long-term relationship between the variables of the model. The value of the coefficient of determination, equal (87\%), indicating that (13\%) of changes in exchange rate attributed to other variables not included in the model. In addition, a statistically significant positive relationship between the exchange rate and (the gross domestic product, openness degree), also statistically significant negative relationship between the exchange rate and (the domestic inflation, money supply, and foreign reserves).
\end{abstract}

This study concluded in a statistically significant relationship between the variables (factors) in the exchange rate model. However, this relationship either positive (GDP, Op) or negative (INF, Ms, and Rs) with the exchange rate in Sudan during the study period.

KEYWORDS: Econometrics, Exchange Rate, Gross Domestic Product, Inflation, Openness Degree, Foreign Exchange Reserves, Money Supply, Stationary Test\& Ordinary Least Square

Received: Feb 28, 2018; Accepted: Mar 19, 2018; Published: Mar 31, 2018; Paper Id.: IJECRAPR20186

\section{INTRODUCTION}

The proposed model for the function of exchange rate determinants in Sudan includes a number of economic variables that have been identifying the economic theory, studies and applied, as the following formula: ex: $f(g d p, r e$, inf, $m s$, open), where:

The Exchange Rate (ex): There are a lot of definitions, such as the price at which a currency is bought or sold against one unit of another currency (Hamzawi, 2004). The importance of the exchange rate in the need of the national economy of any country of foreign currency as the main source of state reserves. In addition, financing imports and 
payment of obligations to outside worldwide.

Gross Domestic Product (GDP): GDP represents the total sum of goods and services manufactured using local production factors. GDP is the most important criterion that reflects the efficiency of the country in using its resources and energy without the use of external resources. The increase in GDP leads to an increase in the volume of exports and thus the stability of the exchange rate (Edgman, 1988).

Foreign Exchange Reserves (Re): Countries usually reserve foreign exchange reserves in their central banks to meet imports and external payments. Large foreign exchange reserves can maintain the exchange rate, especially in the case of fixed exchange rates, and help protect them from a drop that may result from internal or external shocks (Bank of Sudan, 2005, version 7).

Inflation (INF): Is the continuous increase in the general level of prices for a long period. As this impact on the domestic demand for goods, services and consequently increase prices locally. Moreover, affect the prices of exported goods which reduces the ability to compete externally, while at the same time increasing demand for imported goods and adversely affect the moving Current account and hence the balance of payments and hence the stability of exchange rates (Bank of Sudan, 2005, version 7)

Money Supply (Ms): Based on the concept of the exchange rate, any increase in the supply of money would lead to the purchase of a unit. Foreign exchange is the result of any other commodity whose price will be increased for a limited term at least in the short term. However, the increase in the money supply will push the exchange rate upwards and this reflects a direct and strong relationship between money supply and exchange rate and moving in a positive direction. The broad money supply was adopted in this study instead of the tight money supply because the latter does not accurately reflect the amount of cash rolling within the economy and that the broad concept sets the appropriate framework for total cash (AlGalebi, 2011).

Openness Degree (op): Means the scope of cooperation, exchange and integration of the State concerned with other countries in the goods and services, and others, whether on the regional or international level, that is, the foreign trade movement of the State. The degree of openness can be measured by dividing the total exports and imports by the gross domestic product.

The authors noted recently the phenomenon of fluctuations in the exchange rate of the national currency against the US dollar and that there is a relative difficulty in stabilizing the exchange rate of the national currency against other foreign currencies, which had a clear impact on the economic situation in the country.

Thus, explain the relationship between the exchange rate and affected factors, to reach the best standard exchange rate model in Sudan. The study, based on the exchange rate data obtained from the central bank of Sudan and a central bureau of statistics - Sudan. Its determinants (GDP, foreign exchange reserves, domestic inflation, money supply, openness degree) in the period 1972-2013. The study assumes that there is no statistically significant relationship between the exchange rate as a dependent variable and (GDP, foreign exchange reserves, openness degree, domestic inflation and money supply) as independent variables

This study aims to reach the best econometric exchange rate model in Sudan (1972-2013). However, to know the most important factors influence the exchange rate and its formulation in econometric model according to economic theory. Measuring the effect of the economic factors on the exchange rate in Sudan during the study period (1972-2013) 
based on the statistical methods.

\section{MATERIAL \& METHODS}

After describing the econometric model, we obtained accurate data for the variables included in the model. The study faced some problems in terms of lack of data. Also, the difference in the unit of measurement of some variables led to complications resulting from local currency multiplication, which was adopted in the country between the pounds in the eighties of the last century. The dinars in the nineties to the pound again at the beginning of this century have been basing on the reports of the bank of Sudan and the central bureau of Statistics. The study, based on annual data for a period of length to ensure the accuracy and the stability of relationships in the model.

The model was estimated using the (OLS) method based on the stationary tests and the co-integration tests to obtain the most information about the relationships included in the exchange rate model in Sudan (Greene,2003). After selecting the optimum method for estimating the parameters of the model, the study should evaluate the results based on three criteria: (Al Rasheed and Samia, 2010) economic, statistical and econometric criteria. The economic criteria care about signal parameters to be estimated, but the statistical criteria depend on the stationery of the variables included in the model as they help to reach more results that are accurate. On the other hand, test the coefficient of determination to measure the quality estimation of the model. Moreover, to determine the ability of the model to interpret the phenomenon under study as it determines the percentage of total change in the dependent variable interpreted by the independent variables (explained). Moreover, the extent of the significance of the estimated parameters of the model, where the use of the (T-test, F- test).

The study should ensure the safety of the model about the econometric problems that limit the application of one of the assumptions OLS method. The main problems of econometrics are multicollinearity, heteroscedasticity, and autocorrelation (Basam, 2002). However, the model should test the ability prediction where we adopted in this study on the coefficient of inequality of the their (Thiel Inequality Coefficient), which depends on the following assumptions:

Null Hypothesis: The model's ability to predict is high if Thiel coefficient is closer to zero.

Alternative Hypothesis: The model's ability to predict is weak if Thiel coefficient is closer to the correct one.

\section{RESULTS AND DISCUSSIONS}

Part\#1: After analyzing, the data of the study by (E-views) program based on a stationary test (Augmented Dickey-Fuller test) at $(\alpha=0.05)$. However, accept the first-class integration hypothesis at a significant level (5\%) of the variables (GDP, Ms, Op, Re, Inf) where the test value of all these variables is greater than the critical values, that means it's unstable in its level but stable in the first difference. In addition, accept the second-order integration hypothesis for the variable (exchange rate) which means that this variable is unstable in its level but stable in the second difference."Table 1"

Table 1: Unit Root Test for the Study Variables

\begin{tabular}{|c|c|c|c|c|}
\hline Variable & Symbol & Critical Value (5\%) & Value of (ADF) & Difference \\
\hline Exchange Rate & Ex & -2.93 & -5.48 & Second \\
\hline Domestic Gross Product & DGP & -2.93 & -5.36 & First \\
\hline Money Supply & $\mathrm{Ms}$ & -2.93 & -3.07 & First \\
\hline Openness Degree & Op & -2.93 & -5.44 & First \\
\hline Foreign Exchange Reserve & Re & -2.93 & -3.37 & First \\
\hline Inflation & Inf & -2.93 & -4.60 & First \\
\hline
\end{tabular}


The co-integration test (Johnson test) will be used in this study because the model contains more than one independent variable. However, say that the null- hypothesis was rejecting about the absence of co-integration between the variables. The calculated value of the (LR) was greater than the trace value that means have one cointegrating equation at a significant level (5\%)."Table 2"

Table 2: Johnson Test for the Co-Integration

\begin{tabular}{|c|c|c|c|c|}
\hline $\begin{array}{c}\mathbf{1} \% \\
\text { Critical Value }\end{array}$ & $\begin{array}{c}\mathbf{5} \% \\
\text { Critical Value }\end{array}$ & $\begin{array}{c}\text { Likelihood } \\
\text { Ratio }\end{array}$ & Eigenvalue & $\begin{array}{c}\text { Hypothesized } \\
\text { No. of CE(s) }\end{array}$ \\
\hline 54.46 & 47.21 & 49.59992 & 0.492884 & None $*$ \\
\hline 35.65 & 29.68 & 22.43932 & 0.283097 & At most 1 \\
\hline 20.04 & 15.41 & 9.126724 & 0.147863 & At most 2 \\
\hline 6.65 & 3.76 & 2.726384 & 0.065889 & At most 3 \\
\hline
\end{tabular}

The parameters of the model were estimated by the (OLS) method based on (E-views) program. Thus, the values and signals of all model parameters are regular with economic theory and applied studies. In addition, confirm all explanatory variables in the function at a significant level $5 \%$ and compare (t-calculate) for the estimated parameters with (t- tabulated). It's clear that (t-calculated) is greater than (t-tabulated) for all model variables and that indicates a significant relationship between the independent model variables and the dependent variable (Exchange rate). However, a proof the significant of the model based on (F-statistic) which equal (57.3) with significant level (0.000) and it's less than (0.05). In addition, adjusted R-square equal (87\%) which indicates that (13\%) of the change in the dependent variable was belonged to other factors not includes the model. Moreover, that means there is a good relationship between the variables in the exchange rate model in Sudan. "Table 3"

Table 3: Estimation of Exchange Rate Model in Sudan (1972-2013)

\begin{tabular}{|c|c|c|c|c|c|c|c|c|}
\hline Variable & Coefficient & t- Statistic & Prob. & $\begin{array}{l}\text { Adjusted - } \\
\text { R squared }\end{array}$ & F-statistic & $\operatorname{Prob}(F-$-statistic) & DW & Arch. Test \\
\hline $\mathrm{C}$ & 17.353 & -11.59522 & 0.0000 & \multirow{6}{*}{0.87} & \multirow{6}{*}{57.3} & \multirow{6}{*}{0.000000} & \multirow{6}{*}{1.8} & \multirow{6}{*}{0.284} \\
\hline LOG(GDP) & 2.162 & 10.26111 & 0.0000 & & & & & \\
\hline LOG(OP) & 1.057 & 5.003524 & 0.0000 & & & & & \\
\hline MS & -0.000147 & -2.621947 & 0.0127 & & & & & \\
\hline $\mathrm{RS}$ & -0.000853 & -1.885530 & 0.0674 & & & & & \\
\hline LOG(INF) & -0.511760 & -2.759239 & 0.0091 & & & & & \\
\hline
\end{tabular}

The model: $\mathrm{LOGEX}=17.353+2.162 \mathrm{LOG}(\mathrm{GDP})+1.057 \mathrm{LOG}(\mathrm{OP})-0.000147 \mathrm{MS}-0.000853 \mathrm{RS}-$ $0.511760 \mathrm{LOG}(\mathrm{INF})$

After the model based on the economic and statistical criteria, we should check the econometrics criteria, which consists of three problems: multicollinearity, a simple linear correlation matrix is used to detect the linear correlation problem between the independent variables. In addition, we can say the model is clear about this problem if the value of (R-square) between two independent variables is less than (80\%). Our model here is clear about this problem based on Table"4

Table 4: Correlation Matrix between the Model Variables

\begin{tabular}{|c|c|c|c|c|c|}
\hline Variables & MS & GDP & RS & EX & INF \\
\hline MS & 1 & 0.26 & 0.59 & 0.716 & -0.20 \\
\hline GDP & 0.26 & 1 & 0.618 & 0.663 & 0.0047 \\
\hline
\end{tabular}




\begin{tabular}{|c|c|c|c|c|c|}
\hline \multicolumn{7}{|c|}{ Table.4: Contd., } \\
\hline RS & 0.59 & 0.61 & 1 & 0.45 & -0.36 \\
\hline EX & 0.716 & 0.663 & 0.45 & 1 & -0.28 \\
\hline INF & -0.20 & 0.0047 & -0.36 & -0.28 & 1 \\
\hline
\end{tabular}

The exchange rate model did not suffer from the autocorrelation problem, and that based on Durbin-Watson value, $(\mathrm{DW}=2)$ is the standard value. In our model $(\mathrm{DW}=1.8)$ which is approximately equal (2).

Heteroscedasticity problem can be checking be using (ARCH-test), where our model is not suffering from this problem.( Prob. F-statistic) was not significant in the model (0.284) with $\boldsymbol{\alpha}=\mathbf{0 . 0 5}$

Before using estimated models in the forecasting process to plan exchange rate policies, the model's ability to predict should be testing. In many cases, the model may be economical, statistically and econometrically acceptable and statistics for the period in which the sample was taken, but may not be suitable for forecasting because of rapid changes in the structural parameters of relationships in reality. However, based on( Thiel Inequality Coefficient) which is equal (0.026) and its approximately equal zero, which indicates that the exchange rate model can be used for prediction in Sudan.

Part\#2: Analyzing the data of the study by (SPSS) based on multiple regression tests with the options (Enter, Backward, Forward, Stepwise test) at $(\boldsymbol{\alpha}=\mathbf{0 . 0 5})$. The results were similar in (Enter, Backward) and (Forward Stepwise) methods, then the hypothesis:

H0: There is no statistically significant relationship between independent variables and exchange rate.

H1: There is a statistically significant relationship between independent variables and exchange rate.

a. Enter - Backward Method: After analysis data, the correlation coefficient is strong at (81\%) and the adjusted coefficient of (61\%). This indicates that the independent variables explain $(61 \%)$ of the changes in the dependent variable (Ex). However, the variables (GDP, Op, Inf) have no significant effect on the dependent variable (Ex), where we note that the value of Sig for these variables greater than 0.05 which indicates the lack of significance. In addition, the variables (Ms, Re) have a direct relationship with (Ex) and have a significant effect on the value of Sig less than (0.05). Moreover, (Ms) explain (77\%) the change in the (Ex), and the positive sign means increasing in (Ms) increasing in (Ex). In addition, for the variable (Rs) explain (28\%) of the change in (Ex), since $(\mathrm{Re})$ is positive this indicates that the increase in $(\mathrm{Re})$ the increase in exchange rate "table 5"

Table 5: Multiple Regression Results (Enter- Backward Method)

\begin{tabular}{|c|c|c|c|c|c|}
\hline Variable & $\mathbf{R}$ & $\begin{array}{l}\text { Adjusted } \\
\text { R -Square }\end{array}$ & $\begin{array}{c}\text { Unstandardized } \\
\text { Coefficients-B }\end{array}$ & $\begin{array}{c}\text { Standardized } \\
\text { Coefficients-Beta }\end{array}$ & Sig. \\
\hline (Constant) & \multirow{6}{*}{0.809} & \multirow{6}{*}{.607} & .782 & & .001 \\
\hline GDP & & & $-2.363 e-005$ & $-.188-$ & .201 \\
\hline Open & & & $-.336-$ & $-.191-$ & .067 \\
\hline Ms & & & .001 & .766 & .000 \\
\hline Rs & & & .002 & .276 & .013 \\
\hline Inf & & & $-.004-$ & $-.056-$ & .618 \\
\hline
\end{tabular}

Then the best model: $\mathrm{Ex}=0.78+0.001 \mathrm{Ms}+0.002 \mathrm{Rs}$

b. Stepwise - Forward Method: After analysis data, the correlation coefficient is strong at (78\%) and the adjusted coefficient of (58\%). This indicates that the independent variables explain (58\%) of the changes in the dependent variable (Ex). 
However, we found that the variables of (GDP, Op, Inf) have no significant effect on the dependent variable (Ex), where we note that the value of Sig for these variables greater than 0.05 which indicates the lack of significance. Also find that the variables (Ms, Re) have a direct relationship with (Ex) and have a significant effect as the value of Sig less than 0.05 which indicates its significance, where (Ms) explain (64\%) of the change in the (Ex). In addition, since the positive sign means increasing in (Ms) increasing in (Ex). In addition, for the variable (Rs) explain (34\%) of the change in (Ex), since $(\mathrm{Re})$ is positive this indicates that the increase in $(\mathrm{Re})$ the increase in the exchange rate, "Table 6"

Table 6: Multiple Regression Results (Stepwise - Forward Method)

\begin{tabular}{|c|c|c|c|c|c|}
\hline Variable & $\mathbf{R}$ & $\begin{array}{l}\text { Adjusted } \\
\text { R -square }\end{array}$ & $\begin{array}{l}\text { Unstandardized } \\
\text { Coefficients-B }\end{array}$ & $\begin{array}{l}\text { Standardized } \\
\text { Coefficients-Beta }\end{array}$ & Sig. \\
\hline (Constant) & \multirow{6}{*}{0.775} & \multirow{6}{*}{0.580} & .470 & & \\
\hline GDP & & & & -.186 & .178 \\
\hline Open & & & & -.169 & .104 \\
\hline Ms & & & .000 & .640 & .000 \\
\hline Rs & & & .003 & .344 & .002 \\
\hline Inf & & & & -.100 & .353 \\
\hline
\end{tabular}

Then the best model: $\mathrm{Ex}=0.47+0.00 \mathrm{Ms}+0.003 \mathrm{Rs}$

Through the analysis of the study data, which relied on the (SPSS) program through multiple regression analysis and by all available options (Enter, Backward Forward, Stepwise) it was found that the best exchange rate model in Sudan during the study period (1972-2013) using the (Enter, Backward) method, where :

$\mathrm{Ex}=0.78+0.001 \mathrm{Ms}+0.002 \mathrm{Rs}$

This model contains Money supply and foreign reserves as independent variables and the exchange rate as a dependent variable.

\section{CONCLUSIONS}

According to the results of the estimation, conclude that there is a statistically significant positive relationship between the exchange rate with (GDP, Op). Also, there is a statistically significant negative relationship between the exchange rate with (money supply and inflation rate). Moreover, the presence of a statistical significance negative relationship between (Rs) and (Ex). In addition, conclude that the best econometric model for the exchange rate in Sudan during the period of the study (1972-2013) is that model whose contains the money supply and foreign exchange reserves as independent variables with an exchange rate. However, the main factors affect exchange rate in Sudan is money supply and foreign exchange reserves.

\section{RECOMMANDATIONS}

- The money supply and foreign exchange reserves factors had a significant impact on exchange rate model in Sudan. Therefore, the author recommends the development and activation of financial and monetary policies described by scientific, flexibility and realism, especially monetary policy.

- Consolidating the official efforts to motivate and diversify production through the development of flexible, attractive policies and opportunities for different industries to create a climate for them through the development of the agricultural, pastoral and industrial sectors, especially after the secession of the south and the low price of oil. 
- Sudan need to provide political and security stability for an attractive investment climate that attracts foreign capital to the country.

\section{ACKNOWLEDGEMENTS}

Authors are grateful to the Central Bank of Sudan - Statistics and Research Department for providing raw data. However, the Central Bureau of Statistics for their support during the study.

\section{REFERENCES}

1. William H. Greene, "Econometric Analysis", 5th Edition, Prentice Hall, New Jersey, USA, 2003, p654

2. Michael Edgman, Macroeconomics Theory and Politics (Riyadh,Dar al-Marikh for publishing) 1988

3. Mohamed Kamal Al-Hamzawy, Foreign Exchange Market, Knowledge Establishment, Alexandria, 2004.

4. Series of Studies and Research - Central Bank of Sudan, Public Administration for Policies, Research and Statistics, version. 7 (December 2005).

5. Abdul-Hussain Al-Jalil Abdul-Hassan Al-Ghalbi, Exchange Rate and Management (in the Shadow of Economic Shock, Theory and Applications), Amman, Jordan, Dar Al-Safa Publishing and Distribution,2011

6. Abelbaki Cherni, Modeling the Non-Linear Adjustment of the Dinar / Euro Exchange Rate: An Application of the STAR Model, International Journal of Economics, Commerce and Research (IJECR), Volume 6, Issue 2, March-April 2016, pp. 13-26

7. Tariq Mohammed Al-Rasheed, Samia Hassan Mahmoud The Applied Economical Series Using the E-views Program - Current Equation Models, Khartoum: G-Town Press, 2010.

8. Bassam Younes Ibrahim and others, The Econometrics, Dara Azza for Publishing and Distribution, Sudan, 2002. 
